\title{
Decomposing diversity patterns of a soft-bottom macroinvertebrate community in the tropical eastern Pacific
}

\author{
Godínez-Domínguez, E. ${ }^{1,2}$ \\ Freire, J. ${ }^{2}$ \\ Franco-Gordo, C. ${ }^{1,2}$ \\ González-Sansón, G. ${ }^{3}$ \\ ${ }^{1}$ Centro de Ecología Costera, Centro Universitario de la Costa Sur, Universidad de Guadalajara. V Gómez \\ Farías 82. San Patricio-Melaque, Jalisco. México. 38980. \\ ${ }^{2}$ Departamento de Biología Animal, Biología Vegetal y Ecología. Universidad de A Coruña. Campus da \\ Zapateira s/n. A Coruña, España. 15071. egodinez@mail2.udc.es \\ ${ }^{3}$ Centro de Investigaciones Marinas, Universidad de La Habana. La Habana, Cuba.
}

\section{Abstract}

Diversity is one of the most frequently used attributes of ecological communities, and there is a long-standing discussion about their adequate use, calculus and interpretation. One of the most conspicuous and simple diversity estimators is species richness, but it has been criticized by recurrent pitfalls, which has biased comparisons and the testing of hypotheses. Otherwise, synthetic ecological indices of diversity are difficult to interpret due the underlying complex or cryptic concepts. Most of the studies in soft-bottom macroinvertebrate communities trying to estimate richness species, have actually quantified species diversity as species density, the number of species per unit area. In the present study, the diversity of a tropical Pacific soft bottom community is analytically decomposed using two null models to assess species richness and evenness, and the slope of species-area curves to estimate species density. A declining trend of species richness was observed along a 2-year period and could be related to the cumulative effects of interannual environmental variability and fishing disturbance. The species-area relationship could be considered a good indicator of spatial heterogeneity, specifically to illustrate the depth gradient. Local abundance was negatively correlated with evenness, showing that high-density communities are the result of increases in abundance of a few dominant species. Here we demonstrate that seasonality, depth and abundance could explain diversity in soft-bottom macroinvertebrate communities of coastal waters and propose a robust procedure to survey diversity as a part of monitoring programs of coastal management. 
Key words: diversity, evenness, species richness, species-area curve, macroinvertebrate assemblages, tropical Pacific, soft-bottom benthos.

\section{Introduction}

Species richness, species relative abundances, and heterogeneity of their spatial or temporal distributions in a given area are the central subjects of community ecology ( $\mathrm{He}$ and Legendre 2002). Species richness is the simplest way to describe community and regional diversity (Magurran 1988), however its measurement and comparison are still affected by recurrent pitfalls (Gotelli and Coldwell 2001). Communities may differ in measured species richness due to real differences in underlying species richness, to differences in the shape of the relative abundance distribution, or to differences in the number of individuals counted or collected (Denslow 1995). Most of the studies in community ecology of marine habitats published in recent years have pretended to estimate species richness, however several of these studies have actually quantified species diversity as species density, the number of species per unit area (quadrants or swept area) (Gotelli and Coldwell 2001).

Diversity indices have been used recurrently to determine spatial and temporal variation induced by natural and anthropogenic disturbances, and there are numerous references that support this use, however a methodological procedure to find a desirable diversity level for management has been not derived from these papers. Because most diversity indices are sensitive to both evenness and richness, differences can reflect changes in either or both; however changes in evenness should not be interpreted as changes in richness (Levin et al. 2001). In fact, the selection of the most adequate indices is not in the most cases the substantial goal in the search for disturbance evidences, because most of the indices are supported by complex or cryptic concepts and generally they could be correlated (see Washington 1984).

There is now strong evidence that commercial fishing has a profound effect on marine ecosystems (Jennings \& Kaiser 1998, Hall 1999, Kaiser \& de Groot 2000, Trush \& Dayton 2002, Godínez-Domínguez et al in press), however a lack of environmental-impact assessment procedures in fishing management still persists (Thrush et al. 1998). Recently there have been great improvements in our understanding of community level changes in response to fishing (Hall 1999), and species diversity has been considered as a primary subject of the management of 
multispecies fisheries. In contrast, nowadays there are few tropical regions where the soft-bottom species richness had been completely inventoried and accurate richness levels for conservation have bee established (Levin et al. 2001, Gray 2002). Basic patterns, as natural seasonal changes of species diversity and their relation with the depth gradient at local and regional scales remain unknown, impeding the identification of disturbance forces (natural and anthropogenic) that structure the communities (Godínez-Dominguez et al. in press). Natural systems have a great deal of structure in time and space, and it is important to identify thresholds of change in this structure and the processes involved to gauge ecosystem resilience (Thrush \& Dayton 2002)

Spatiotemporal variation in benthic species diversity represents the integration of ecological and evolutionary processes that operate at different spatial and temporal scales (Levin et al. 2001), and if we want to understand diversity, we should look for mechanisms that influence the abundances and spatial distribution of species (He and Legendre 2002). Here, diversity of the soft-bottom macroinvertebrate assemblage inhabiting the tropical eastern Pacific is analytically decomposed using estimates of richness, evenness, and species density. These measures could explain the basic and conspicuous structural traits of the macroinvertebrate diversity. The relations among the diversity and spatial and temporal environmental variability were modeled. Finally we discuss the relationships of the results obtained with the survey scale and their management implications.

\section{Material and Methods}

\section{Sampling}

The study area is located on the continental shelf in the Mexican central Pacific (Fig. 1), between the 10 and $90 \mathrm{~m}$ isobaths, from Punta Farallón (Jalisco) to the mouth of the Cuitzmala River to Cuyutlán (Colima). The continental shelf of this region is very narrow, comprising, up to the $200-\mathrm{m}$ isobath, only $7-10 \mathrm{~km}$ (Filonov et al. 2000). The predominant surface current patterns in the study area are described by Wyrtki (1965) for the eastern Pacific Ocean, consisting of the two main phases: the first one is influenced by the California Current, and it is characterized by a cold water mass from January-February to April-May; the second phase is a period (July-August to November-December) influenced by the North Equatorial Countercurrent and characterized by a tropical water mass. A third phase is determined by a transition between both previous phases neither one dominating. This hydroclimatic seasonality 
is the most influent force that determines the temporal patterns of the macroinvertebrate community in the zone (Godínez-Domínguez et al. in press).

Five cruises (DEM 1 to DEM 5) were conducted aboard the r.v. BIP-V during the different hydroclimatic seasons: May-June (transition) and November-December (tropical) 1995, and March (subtropical-temperate), June (transition) and December (tropical) 1996. Samplings were taken with a otter trawl gear (cone-shaped bag, one net per side of the boat) used in the commercial shrimp fisheries in the Mexican Pacific. The gear used varied respect to the commercial gears in its reduced size $(6.9 \mathrm{~m}$ of mouth) and reduced mesh size (38 $\mathrm{mm}$ in the cod end). Seven sites were selected along the coast according to the spatial distribution of soft bottoms and to the commercial shrimp fleet preferences. Four depth strata were selected (20, 40, 60 and $80 \mathrm{~m}$ ) for each site making a total of 28 sampling stations per cruise. Each tow lasted $0.5 \mathrm{~h}$ corresponding to an average of one hectare trawled by sampling station. The sampling order of the sites was randomly selected and all the samples from a same site were taken the same night in a random way. Samples were preserved on ice and processed immediately; organisms were identified taxonomically, counted and the fresh weight by species was recorded. In the present study, all the macroinvertebrate groups in catches were included (cnidarians, mollusks, crustaceans, and echinoderms).

Diversity estimates for each cruise were calculated per depth strata, and the seven sampling sites were considered as replicates. Evenness and species richness were estimated using two null models. Evenness was estimated using the probability of an interspecific encounter PIE (Hurlbert 1971):

$$
P I E=\left(\frac{N}{N-1}\right)\left(1-\sum_{i=1}^{S} p_{i}{ }^{2}\right)
$$

Where $\mathrm{N}$ equal the total number of individuals in the collection, and $p$ (i) represent the proportion of the entire sample represented by species $i$. $S$ is the total number of species in the collection and $m_{i}$ is the number of individuals of species $i$ in the collection. This index gives the probability that two randomly sampled individuals from the assemblage represent two different species, and is characterized by two main attributes: first is easily interpreted as a probability, and second this index is one of the 
few that is unbiased by sample size, although variance increases with small N (Gotelli and Entsminger 2001).

Species richness was estimated using rarefaction curves (Gotelli and Graves 1996), which generate comparative estimates of species number independently of the differences in sampling sizes of the groups compared. An individual-based procedure was used in the rarefaction estimation. The abundance levels for simulations were established using the sample with to the lowest abundance (700 organisms) to allow the comparison between expected richness and evenness among the samples. Both evenness and rarefaction were estimated using EcoSim software (Gotelli and Entsminger 2001), which uses a Monte Carlo procedure, and 1000 replicate simulations were performed for each estimate. Samples are drawn randomly without replacement, and the procedure is repeated 1000 times to estimate an average value and confidence interval (95\%) at several abundance levels.

The species-area curve (Rosenzweig, 1995) was used as a species density index:

$$
S=a A^{\beta}
$$

where $S$ is the species richness, $A$ the trawled area, the intercept $a$ is related to overall species richness and the slope $\beta$ constitutes an index of species density.

Generalized linear models (GLM) were employed to determine the relations between indices of diversity (species richness, evenness) and the slope of speciesarea curves and environmental spatiotemporal factors (season and depth) and organism abundance (local: average per depth strata, and regional: average for the complete sampling area per cruise). A normal log model was assumed, and the best subset procedure based on the Akaike information criterion (AIC) was used to select the most parsimonious model.

\section{Results}

A marked temporal trend in species richness was observed along the study period (Fig 2). The highest richness was observed during the DEM 1 cruise declining gradually toward the last cruise, 2 years later. A similar richness-depth pattern was observed in the DEM 1 and 4 cruises; with a higher number of species observed in 
shallow (20 and $40 \mathrm{~m}$ ) than in deep waters $(60$ and $80 \mathrm{~m})$. In shallow waters the average species richness was 45 and 25 (expected number of species) in DEM 1 and DEM 4 respectively, whereas in deepest waters the expected richness was 33 and 15. Cruises DEM 1 and 4 were carried out in the same hydroclimatic season (transition between tropical and subtropical-temperate period), and a similar bathymetric pattern of assemblage organization has been reported elsewhere (Godínez-Domínguez et al. in press). Cruises DEM 2 and 5 were carried out in the tropical period but they showed a different richness-depth pattern. During Cruise DEM 2 the highest richness was estimated in the shallowest stratum (20 m, 34 species), while in DEM 5 the overlapping of the confidence intervals indicate similar richness among strata (range: 11-18 species). Cruise DEM 3 (subtropical-temperate season) showed a similar richness in the different depth strata ranging from 24 to 30 species. The distribution along the depth gradient of the macroinvertebrate assemblages (described in GodínezDomínguez et al. in press) was similar in Cruises DEM 2, 3 and 5, and in all cases different assemblages characterized each of one of the depth strata.

No temporal trend could be detected in evenness (Fig 3). The highest PIE values in DEM 1 and 4 (transition period) were obtained at $20 \mathrm{~m}$ (0.88 and 0.84 , respectively). In tropical seasons (DEM 2 and 5) evenness and depth showed contrasting patterns; while in DEM 5 evenness increased with depth, in DEM 2 decreased. In DEM 3, PIE values were in general high and fluctuated in a narrow range of 0.64 to 0.80 .

No time trends were observed in the slope of the species-area curves (Fig. 4). However a general inverse trend in relation with depth could be observed and two groups, shallow (20 and $40 \mathrm{~m}$ ) and deep (60 and 80 ) of slope values could be discriminated. Correlation among diversity indices and local abundance were estimated. Species richness and evenness showed a positive correlation $(p<0.05)$ (Fig. $5)$, while the species-area slope did not showed significant $(p>0.05)$ relations with richness or evenness. Abundance only showed a significant negative correlation with the evenness.

The model selected for evenness using GLM included the environmental variables (depth, season and their interaction) and local abundance (Table 1). The best model for species richness included both abundance estimates, seasonality and depth but not their interaction. The most parsimonious model explaining the slope of the species-area curve included regional abundance, depth and the season-depth 
interaction. Only depth was included as independent variable in all the models fitted. From the analysis of the GLM coefficients, a decrease in evenness was detected during the transition. The shallow strata $(20$ and $40 \mathrm{~m})$ showed highest evenness values, while increased in local abundance were associated with decreases in evenness. The species richness attained a minimum during tropical period and a maximum in the transition. The richness at $40 \mathrm{~m}$ was higher than in other depth strata, while the relation with the regional abundance was negative. The slope of species-area curve shows a positive relation with the regional abundance, and is lowest at $60 \mathrm{~m}$ than in other depths. The AIC procedure of model construction consider variables that individually could be statistically significant or not, and for this reason there are variables that showed significant fits but were not selected in the most parsimonious model as in the slope model, and by other hand, there are variables with nonsignificant individual fits that were included in the most parsimonious models (see Table 1)

\section{Discussion}

The standardization of area or sampling effort may produce very different results compared to standardizing by number of individuals collected. Rarefaction methods used with both sample-based and individual-based procedures could produce contradictory results, and these differences could be explained by spatial patchiness patterns (Gotelli and Colwell 2001). We have used a fixed number of organisms determined by the lowest sample size (700 organisms) to calculate species richness and evenness with the individual-based procedure, according to Gotelli and Colwell (2001) and Levin et al. (2001), to allow comparisons. The PIE evenness index is unbiased by sample size but comparisons of species richness are affected by abundance (Rosenzweig 1995). For this reason it is important to use the species accumulation curve to quantify taxon richness, even in studies in which sampling effort is carefully standardized (Gotelli and Colwell 2001), as in the present case.

The declining trend of species richness observed in the present study could be related to the cumulative effects of interannual environmental variability and fishing disturbance. This study was carried out previous the most important El Niño event (1997-1998) of the 20th century (Philander 1999), and a fishing-induced state of chronic disturbance has been reported in this community (Godínez-Domínguez et al. in review). The ENSO effects in the benthic communities remain unknown, and by other hand, trawling on soft-bottoms produces disturbances at several scales, modifying 
habitat structure and inducing sediment homogenization (Jennings and Kaiser 1998, Thrush \& Dayton 2002), and affecting biodiversity at broad-scales. Besides there is not possible to discriminate disturbance sources (anthropogenic and natural) in the benthic community studied, environmental disturbances like interannual variability could be more influent than fishing (Godínez-Domínguez et al. in review).

Disturbance regimes play a key role in influencing biodiversity (Connell 1978). Although the fishing effort in most fisheries is non-evenly distributed in space, fishing impacts are perceived at a broad or regional scale (Kaiser \& Spencer 1996, Thrush et al. 1998). Fishing disturbance and recovery time depend on species, type of gear, habitat and frequency of disturbance (Collie et al. 2000). However often the scales of measurement of fishing effort are difficult to match with ecological effects, as they do not match well with scales of variability in seafloor ecological communities (Thrush and Dayton 2002). Papers that approach the relation between fishing disturbance and biodiversity, differs in the assemblage response (Kaiser \& Spencer 1996, Kaiser et al. 1998, Pranovi et al. 2000, Sánchez et al. 2000, Thrush et al. 1998, Tuck et al. 1998, Veale et al. 2000, Godínez-Domínguez et al. in press). However this inconsistence of the results could be attributed to the forms of diversity measurement (species richness, diversity indices, species density, abundance and composition), lacking of a priori hypotheses, and confounding the scale of the surveys.

Bathymetric patterns in evenness and species richness are variable in different cruises and within the same hydroclimatic season. Although evenness and richness showed a strong correlation, species richness could be a better indicator of temporal variability. The species-area relationship could be considered a better indicator of spatial heterogeneity specifically to illustrate the depth gradient. Evenness is related to abundance variability as indicated by their high correlation. According to Thrush et al. (2001) diversity components could be related with scale and the relative importance of physical and biological elements of habitat structure vary with spatial scale. Two main relationships are deduced of most of papers focused in the estimation of diversity on soft-bottom demersal fish and macrobenthic communities: diversity-depth (Coleman et al. 1997, Gray et al. 1997, Bianchi 1991) and diversity-scale (Thrush et al. 2001, Thrush and Dayton 2002). Despite that the richness-depth relation in soft-bottom communities has been a topic widely reviewed (Grassle and Maciolek 1992, Gray 1994, Coleman et al. 1997, Levin et al. 2001, Gray 2002) there is still a controversy about conceptual and methodological aspects of the relationship along the latitudinal and depth gradient, although they coincide that the model that better explain the 
response of the diversity to these gradients could be unimodal (Levin et al. 2001, Gray 2002), at least for depth in some taxonomical groups. Of course this unimodal gradient is evidenced only when a large depth range is analyzed. Actually, the depth-diversity relationship is contained in the diversity-scale relationship, and most of the controversy derived from the depth-diversity relationship is due to differences in scale of the surveys, sampling effort and numerical procedures to estimate diversity (Levin et al. 2001, Gray 2002).

Rosenzweig (1995) suggested that the number of species in an area was likely related to habitat richness of that area, since areas of greater richness offer new niches for colonizing species. Therefore areas with greater habitat richness should have more species per unit area, resulting in steeper slopes of the species-area curves. The hypothesis that habitat richness decreases with depth appears reasonable even in a short depth gradient (in our case 10-90 m). The inshore zone (including sheltered and exposed areas) in tropical latitudes constitutes nurseries (Blaber \& Blaber 1981) and it is recognized as ecologically conspicuous and containing diverse habitats (Longhurst \& Pauly 1987). The interior shelf is characterized by high-energy flows, tidal cycles and current patterns that cause a dynamic water column (Darnell, 1990), and could be related with the high heterogeneity and dynamics of the seabed. The "habitat diversity hypothesis" (Anderson 1998) is probably the better conceptual model proposed to explain the ecological or statistical processes underlying the species-area relationship in the tropical Pacific shelf.

The inverse relation between evenness and abundance is a topic widely studied and could represent an ecological feature of the community studied; increases in abundance are due to an increase in the dominance of a few species and states of high abundance with high evenness are not a frequent situation. According to $\mathrm{He}$ and Legendre (2002), if a mechanism can make the species abundances more even, or their spatial distribution more regular, this factor should contribute to species coexistence, and vice versa. In communities with high dominance sub-estimation of species richness is more probable due to the high number of organisms needed to find new species, and for this reason, sampling deficiencies in these communities are expected more frequently. We considered that species accumulative curves are necessary to demonstrate sample sufficiency.

The coupling between diversity and assemblage patterns (described by Godínez-Domínguez and Freire 2003 and Godínez-Domínguez et al. in press) has not 
been appreciated. Changes in assemblage structure are not followed always by diversity changes at the same scale (Gray 2003). Assemblages can vary within small depth ranges (Bergen et al. 2001, Godínez-Domínguez and Freire 2003) but species richness change over larger scales (Rex et al. 1993, 2000, Gray et al. 1997). This could be the reason because several analyses cannot conciliate their results from multivariate ordinations of assemblage matrices and diversity indices estimates at the same scale. These results force usually the search for more "sensitive" indices trying to conciliate patterns when the real problem is related to scale.

We made tows of 1 ha at each depth and small-scale heterogeneity was not considered in data, but this level of heterogeneity is not relevant to account for diversity at broad scales (the fisheries scale) or when the depth-diversity relationship is analyzed. However, in marine benthic habitats small-scale natural disturbances play an important role influencing communities by generating patchiness (Dayton 1994, Hall et al. 1994, Sousa 1984), and heterogeneity is an important component of the functioning of ecological systems (Kolasa \& Pickett 1991, Legendre 1993) and has implications for the maintenance of diversity and stability at the population, community and ecosystem levels. In soft-bottom habitats the creation of small-scale habitat structure by biogenic features can play key roles in influencing diversity and resilience (Thrush and Dayton 2002). In most of the fishing-disturbance surveys, several patchings are crossed in each sampling tow and this heterogeneity level only could be reflected in a ratio variance/mean. Species within a local assemblage (1-10 $\left.\mathrm{m}^{2}\right)$ are controlled by small-scale processes involving resource partitioning, competitive exclusion, predation, facilitation, physical disturbance, recruitment, and physiological tolerances, all of which are mediated by the nature and degree of heterogeneity (Levin et al. 2001). At regional scales (100s to 1000 s of $m$, several environmental gradients, dispersal, metapopulation dynamics, and gradients in habitat heterogeneity are likely to be important (Levin et al. 2001).

\section{Acknowledgements}

This research was partially founded by the University of Guadalajara and the Consejo Nacional de Ciencia y Tecnología CONACyT Mexico, and by the grant REN2000-0446 from the Spanish Ministerio de Ciencia y Tecnología. To rv BIP V's crew and the "Demersales project" staff for their help during field phase and to Victor 
Landa Jaime, Rafael García de Quevedo Machaín, and Judith Arciniega Flores for taxonomical support.

\section{Literature cited}

Anderson, M.J. 1998 Effects of patch size on colonization in estuaries: revisiting the species-area relationship. Oecologia, 118: 87-98

Bergen, M., Weisberg, S.B., Smith, R.W., Cadien, D.B., Dalkey, A., Montagne, D.E., Stull, J.K, Velarde, R.G \& Ranasinghe. J.A. (2001) relationship between depth, sediment latitude and the structure of benthic infaunal assemblages on the mainland shelf of southern California. Marine Biology, 138: 637-647

Bianchi, G. 1991 Demersal assemblages of the continental shelf and slope edge between the Gulf of Tehuantepec (Mexico) and the Gulf of Papagayo (Costa Rica). Marine Ecology Progress Series, 73: 121-140

Blaber, S.J.M. \& Blaber, T.G. 1981 The zoogeographical affinities of estuarine fishes in South-East Africa. South African Journal of Science, 77, 305-307.

Coleman, N., Gason, A.S.H. \& Poore, G.C.B. 1997 High species richness in the shallow marine waters of southeast Australia. Marine Ecology Progress Series, 154: $17-26$

Collie, J., Hall S., Kaiser M., \& Poiner I., 2000. A quantitative analysis of fishing impacts on shelf-sea benthos. Journal of Animal Ecology, 69, 785-798.

Connell, J.H., 1978. Diversity in tropical rainforests and coral reefs. Science, 199, 1302-1310.

Darnell, R.M. 1990 Mapping of the biological resources of the continental shelf. American Zoologist, 30, 15-21.

Dayton, P. K. 1994 Community landscape: scale and stability in hard bottom marine communities. In Hildrew AG, Giller PS, Raffaelli D (eds) Aquatic ecology: scale, pattern and processes. Blackwell Scientific, Oxford, p 289-332 
Denslow, J. 1995 Disturbance and diversity in tropical rain forest: the density effect. Ecological Application, 5: 962-968

Filonov, A.E., Tereshchenko, I.E., Monzon, C.O., González-Ruelas, M.E., \& GodínezDomínguez, E. 2000 Variabilidad estacional de los campos de temperatura y salinidad en la zona costera de los estados de Jalisco y Colima, México. Ciencias Marinas, 26(2): 303-321

Godínez-Domínguez, E. \& Freire, J. 2003 Information-theoretic approach for selection of spatial and temporal models of community organization. Marine Ecology Progress Series, 253: 17-24.

Godínez-Domínguez, E., Freire, J. \& González-Sansón, G. (in press) Hierarchical. Organization of spatial and temporal patterns of epibenthic assemblages in the tropical Pacific continental shelf. Marine Biology

Gotelli, N.J. \& Graves, G.R. 1996 Null models in ecology. Smithsonian institution press. Washington.

Gotelli, N.J. \& Colwell, R.K. 2001 Quantifying biodiversity: procedures and pitfalls in the measurement and comparisons of species richness. Ecological Letters, 4: 379391

Gotelli, N.J. \& Entsminger, G.L. 2001 EcoSim: Null models software for ecology. Version 7.0. Acquired Intelligence Inc. \& Kesey-Bear. http://homepages.together.net/ gentsmin/ecosim.htm.

Grassle, J.F. \& Maciolek, N.J. 1992 Deep-sea species richness; regional and local diversity estimates from quantitative bottom samples. American Naturalist, 139: 313-340

Gray, J.S. 1994 Is deep-sea species diversity really so high? Species diversity of the Norwegian Continental shelf. Marine Ecology Progress Series, 112: 205-209

Gray, J.S. 2002 Species richness of marine soft sediments. Marine Ecology Progress Series, 244: 285-297 
Gray, J.S. 2003 Species richness of marine soft sediments. Marine Ecology Progress Series, 244: 285-297

Gray, J.S., Poore, G.C.B., Ugland, K.I., Wilson, R.S., Olsgard, F. \& Johannessen, O. 1997 Coastal and deep-sea benthic diversities compared. Marine Ecology Progress Series, 159: 97-103

Hall, S.J., Raffaelli, D. \& Thrush, S.F. 1994. Patchiness and disturbance in shallow water benthic assemblages. In: Giller, P.S., Hildrew, A.G., and Raffaelli, D. (Eds.), Aquatic ecology: scale, pattern and process. Blackwell Scientific Publications, Oxford, pp 333-376.

Hall, S.J. 1999 The effects of fishing on marine ecosystems and communities. Blackwell Science, Oxford, 274 pp

He, F. \& Legendre, P. 2002 Species diversity patterns derived from species-area models. Ecology, 83: 1185-1198

Hurlbert, S.M. 1971 The non-concept of species diversity, A critique and alternative parameters. Ecology, 52: 577-586

Jennings, S. \& Kaiser, M.J. 1998 The effects of fishing on marine ecosystems. Advances in Marine Biology, 34: 203-314

Kaiser, M., \& Spencer, B. 1996 The effects of beam-trawl disturbance on infaunal communities in different habitats. Journal of Animal Ecology, 65, 348-358.

Kaiser, M.J., Armstrong, P.J., Dare, P.J. \& Flatt, R.P. (1998) Benthic communities associated with a heavily fished scallop ground. Journal of the Marine Biological Association of the United Kingdom 78: 10451059.

Kaiser, M., Ramsay, K., Richardson C.A., Spence, F.E. \& Brand A.R. 2000 Chronic fishing disturbance has changed shelf sea benthic community structure. Journal of Animal Ecology, 69: 494-503 
Kolasa, J. \& Pickett, S.T.A. 1991 Ecological heterogeneity. Springer Verlag, New York, $332 \mathrm{p}$

Levin, L.A., Etter, R.J. Rex, M.A. Gooday, A.J. Smith, C.R. Pineda, J. Stuart, C.T. Hessler, R.R. \& Pawson, D. 2001 Environmental influences on regional deepsea species diversity. Annual Reviews of Ecology and Systematics, 32: 51-93

Longhurst, A.R. \& Pauly, D. 1987 The ecology of tropical oceans. Academic Press, Orlando, Florida.

Magurran, A.E. 1988 Ecological diversity and its measurement. Princeton University Press, Princeton USA

Philander, S. G. H. (1999) A review of tropical ocean-atmosphere interactions. Tellus $A-B(1): 79-90$

Pranovi, F., Raicevich, S., Franceschini, G., Farrace, M.G. \& Giovanardi, O. 2000 Rapido trawling in the northern Adratic Sea effects on benthic communities in an experimental area. ICES Journal of Marine Sciences, 57: 517-524

Rex, M.A., Stuart, C.T. Hessler, R.R. Allen, J.A. Sanders, H.L. \& Wilson, G.D.F. 1993 Global-scale latitudinal patterns of species diversity in the deep-sea benthos. Nature, 365: 636-639

Rex, M.A., Stuart, C.T. \& Coyne, C. 2000 Latitudinal gradients of species richness in the deep-sea benthos of the North Atlantic. Proceedings of National Academy of Sciences USA, 97: 4082-4085

Rosenzweig, M.L. 1995 Species in space and time. Cambridge Univ Press. Cambridge $436 p$

Sanchez, P., Demestre, M., Ramon, M., Kaiser, M.J. 2000 The impact of otter trawling on mud communities in the Northwestern Mediterranean. ICES Journal of Marine Science, 57: 1352-1358

Sousa, W.P. 1984 Intertidal mosaics: patch size, propagule availability, and spatially variable patterns of sucession. Ecology 65: 1918-1935 
Thrush, S.F, Hewitt, J.E, Cummings, V.J., Dayton, P.K., Cryer, M., Turner, S.J., Funnell, G.A., Budd, R.G., Milburn, C.J. and Wilkinson M.R. 1998. Disturbance of marine benthic habitat by commercial fishing impacts at the scale of the fishery. Ecological Application, 8: 866-879.

Thrush, S.F., Hewitt, J.E., Funnell, G.A., Cummings, V.J. \& 4 others 2001 Fishing disturbance and marine biodiversity: role of habitat structure in simple softsediments systems. Marine Ecology Progress Series, 221: 255-264

Thrush, S.F. \& Dayton, P.K. 2002. Disturbance to marine benthic habitats by trawling and dredging: implications for marine biodiversity. Annual Review of Ecology and Systematics, 33: 449-473

Veale, L.O., Hill, A.S., Hawkins, S.J. \& Brand, A.R. 2000 Effects of long-term physical disturbance by commercial scallop fishing on subtidal epifaunal assemblages and habitats. Marine Biology, 137: 325-337

Washington, H.G. 1984 Diversity, biotic and similarity indices. Water Research, 18: 653-694

Wyrtki, K. 1965 Surface currents of the Eastern Tropical Pacific Ocean. Inter-American Tropical Tuna Comission Bull, IX: 271-304 


\section{Figure Captions}

Figure 1. Study area. The shaded rectangles indicate the sampling sites.

Figure 2. Rarefaction curves for each cruise and depth strata of the macroinvertebrate assemblages. Solid lines represent the average of the richness estimates, and dotted lines are the $95 \%$ confidence intervals.

Figure 3. Evenness (Probability of an interspecific encounter) estimated for each cruise and depth strata of the macroinvertebrate assemblages. Solid lines represent the average of the evenness estimates, and dotted lines are the 95\% confidence intervals.

Figure 4. Slopes of species-area curves estimated for each cruise and depth strata.

Figure 5. Relationship among the different diversity indices and local abundance. Linear regression are showed for significant relationships $(p<0.05)$ 


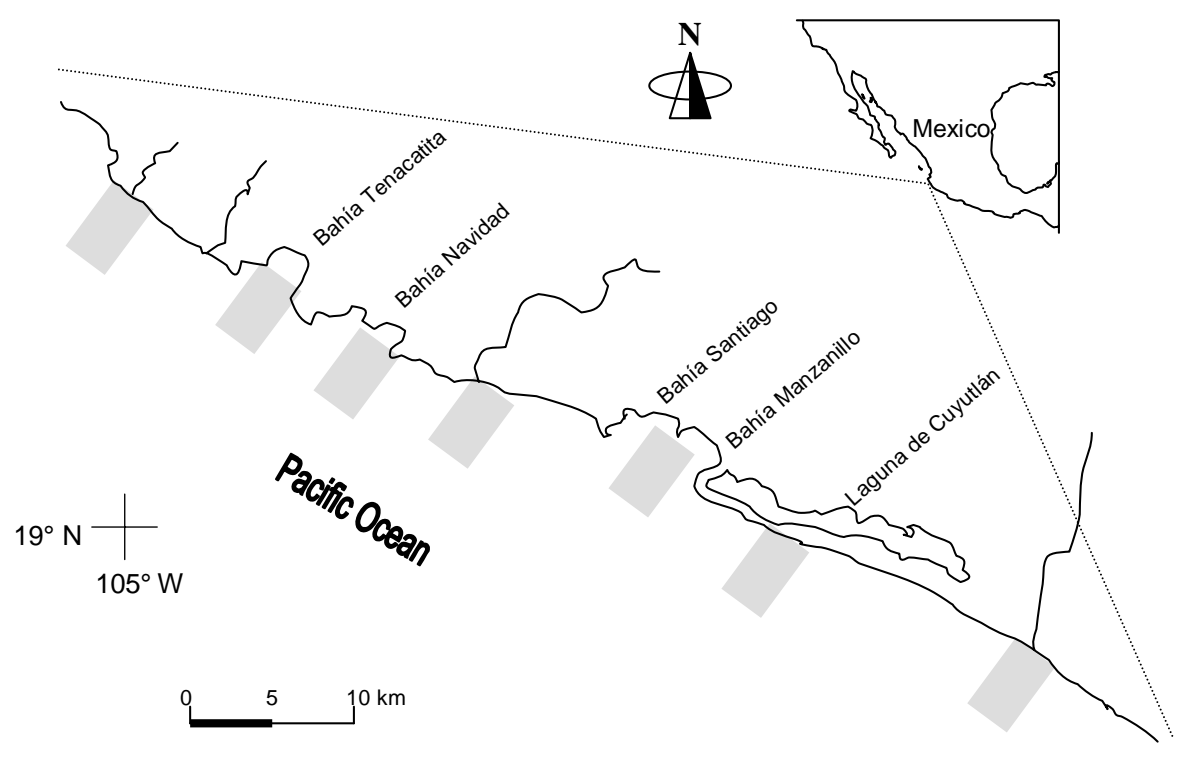

Fig.1 


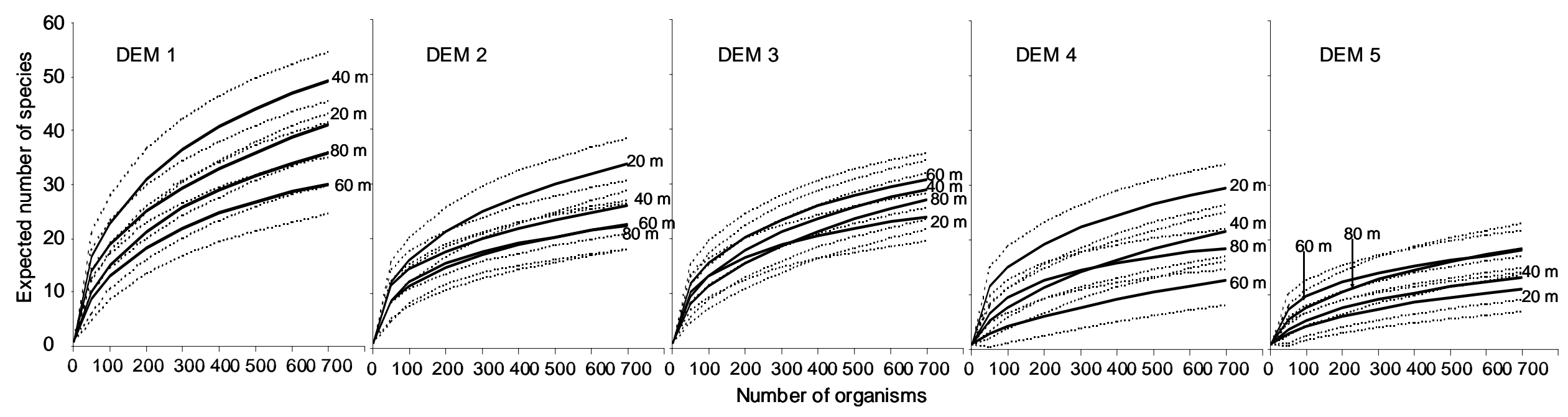

N

ब.

N 


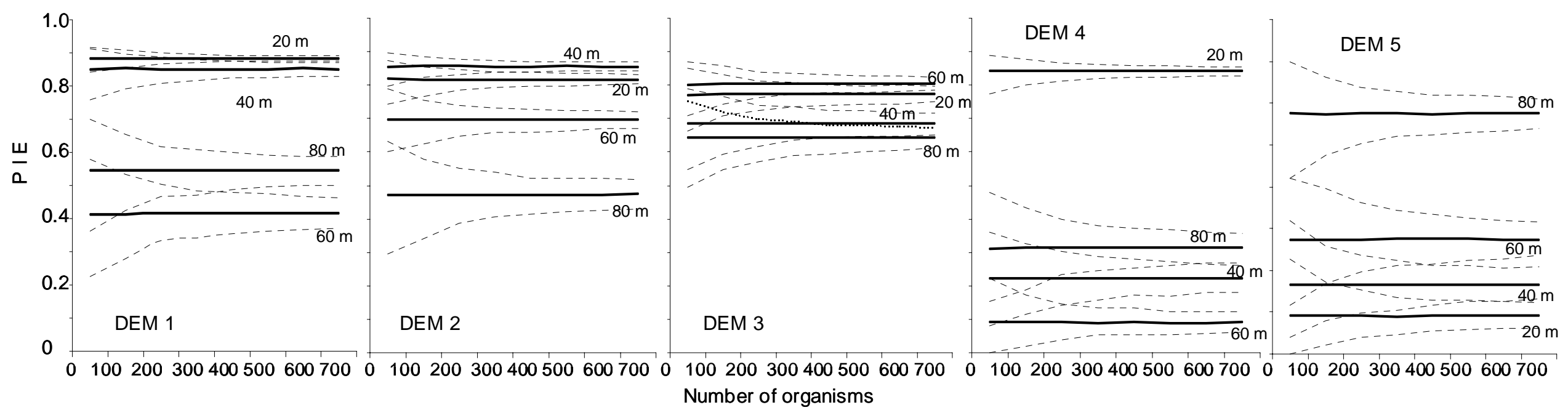

79
0
0 


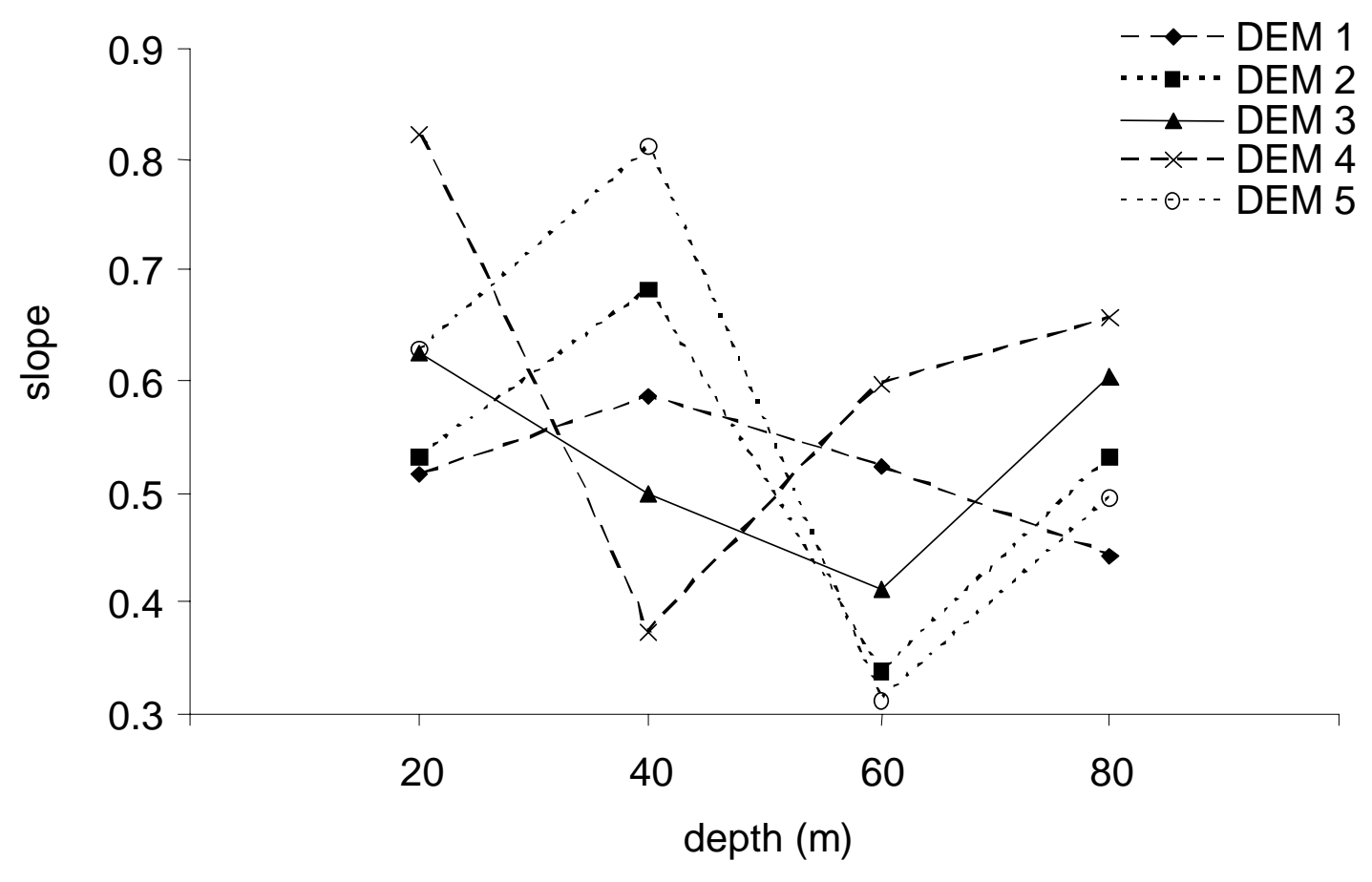

Fig. 4 

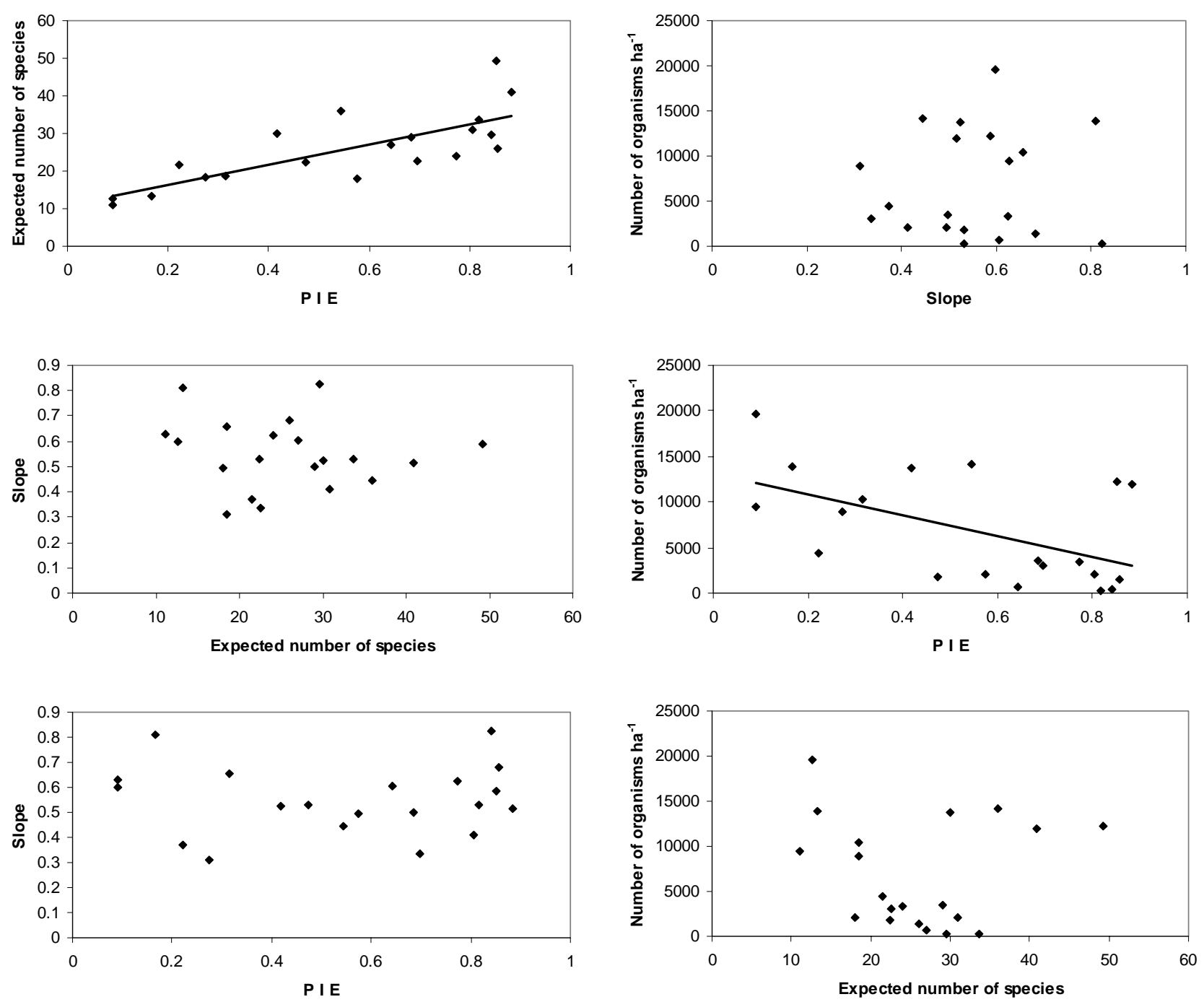
Table 1. Parameters of models relating diversity indices (species richness, evenness, slope of species-area curves) with environmental variables

(depth, season) and abundance (local and regional). Selected model is the most parsimoniuos model (GLM) according to Akaike information criterion (AIC)

\begin{tabular}{|c|c|c|c|}
\hline Evenness & $\begin{array}{l}\text { Level of } \\
\text { effect }\end{array}$ & Coefficient & p \\
\hline Intercept & & -0.07 & 0.225 \\
\hline local abundance & & $-1.68 E-04$ & $<0.001$ \\
\hline regional abundance & & $-3.81 E-06$ & 0.775 \\
\hline season & transition & -0.17 & $<0.001$ \\
\hline season & tropical & 0.01 & 0.701 \\
\hline depth & 20 & 0.09 & 0.054 \\
\hline depth & 40 & 0.12 & 0.012 \\
\hline depth & 60 & 0.05 & 0.478 \\
\hline season*depth & transition ${ }^{\star} 20$ & 0.06 & 0.394 \\
\hline season*depth & transition*40 & -0.06 & 0.413 \\
\hline season*depth & transition $* 60$ & -0.17 & 0.082 \\
\hline season*depth & tropical $^{\star 20}$ & -0.20 & 0.002 \\
\hline season*depth & tropical $^{*} 40$ & 0.04 & 0.556 \\
\hline season*depth & tropical $^{*} 60$ & 0.17 & 0.024 \\
\hline Scale & & 0.07 & $<0.001$ \\
\hline
\end{tabular}

Selected model: d.f. $12, \quad p<0.001$

Evenness $=$ depth + season + local abundance $+\left(\right.$ season $^{\star}$ depth $)$

\begin{tabular}{|c|c|c|c|}
\hline \multicolumn{4}{|l|}{ Richness } \\
\hline Intercept & & 3.57 & $<0.001$ \\
\hline local abundance & & $-3.77 \mathrm{E}-05$ & $<0.001$ \\
\hline regional abundance & & $-5.29 E-05$ & $<0.001$ \\
\hline season & transition & 0.19 & $<0.001$ \\
\hline season & tropical & -0.14 & $<0.001$ \\
\hline depth & 20 & 0.03 & 0.428 \\
\hline depth & 40 & 0.08 & 0.015 \\
\hline depth & 60 & -0.03 & 0.480 \\
\hline season*depth & transition ${ }^{\star} 20$ & 0.02 & 0.607 \\
\hline season*depth & transition*40 & 0.07 & 0.098 \\
\hline season*depth & transition $* 0$ & -0.13 & 0.010 \\
\hline season*depth & tropical $^{\star} 20$ & 0.10 & 0.039 \\
\hline season*depth & tropical $^{\star} 40$ & -0.09 & 0.086 \\
\hline season*depth & tropical*6 & 0.03 & 0.592 \\
\hline Scale & & 2.22 & $<0.001$ \\
\hline
\end{tabular}

Selected model:

d.f. $7, \quad p<0.002$

Richness $=$ depth + season + regional abundance + local abundance

\begin{tabular}{|c|c|c|c|}
\hline \multicolumn{4}{|c|}{ Slope of species-area curve } \\
\hline Intercept & & -0.72 & $<0.001$ \\
\hline local abundance & & $2.51 \mathrm{E}-07$ & 0.980 \\
\hline regional abundance & & 2.13E-05 & 0.102 \\
\hline season & transition & 0.03 & 0.447 \\
\hline season & tropical & -0.06 & 0.168 \\
\hline depth & 20 & 0.16 & 0.001 \\
\hline depth & 40 & 0.04 & 0.373 \\
\hline depth & 60 & -0.24 & $<0.001$ \\
\hline season*depth & transition*20 & 0.03 & 0.630 \\
\hline season*depth & transition*40 & -0.22 & 0.003 \\
\hline season*depth & transition*60 & 0.24 & 0.005 \\
\hline season*depth & tropical²0 & -0.04 & 0.498 \\
\hline season*depth & tropical*40 & 0.33 & $<0.001$ \\
\hline season*depth & tropical*60 & -0.23 & 0.008 \\
\hline Scale & & 0.06 & $<0.001$ \\
\hline
\end{tabular}

Slope $=$ depth + regional abundance $+\left(\right.$ season ${ }^{*}$ depth $)$ 